\title{
1 The combined effects of questioning technique and interviewer manner on \\ 2 false confessions
}

3

4 Wendy Paton ${ }^{1,2}$ Stella A. Bain ${ }^{1}$ Lynsey Gozna ${ }^{3}$ Elizabeth Gilchrist ${ }^{1,4}$ Derek Heim ${ }^{5}$ Euan Gardner ${ }^{1}$

5 David Cairns ${ }^{1,6}$ Paul McGranaghan ${ }^{1,7}$ Rico Fischer ${ }^{1,8}$

6

71 Department of Psychology, Social Work and Allied Health Sciences, Glasgow Caledonian University,

8 Glasgow, UK

92 School of Social Sciences, Humanities \& Law, Teesside University, Middlesbrough, UK

3 Department of Neuroscience, Psychology and Behaviour, University of Leicester, Leicester, UK

4 Institute of Health and Society, University of Worcester, Worcester, UK

5 Department of Psychology, Edge Hill University, Ormskirk, UK

6 Department of Psychological Sciences \& Health, University of Strathclyde, Glasgow, UK

7 Department of Philosophy, Psychology and Language Sciences, University of Edinburgh, Edinburgh, UK

8 School of Psychology \& Neuroscience, University of St Andrews, St Andrews, UK

Correspondence:

Wendy Paton, School of Social Sciences, Humanities \& Law, Teesside University, Middlesbrough,

Tees Valley, TS1 3BX, UK. Email: w.paton@tees.ac.uk

\section{Abstract}

Although it is known that interrogation tactics can elicit false confessions and interviewer manner may determine the outcome of an interview, the combined effects of questioning technique and interviewer manner on false confessions have not been examined empirically. Following a false accusation of theft, participants were interviewed in one of four questioning conditions (minimisation, repetitive questioning, leading questions, and nonleading questions) in which interviewers adopted a stern or friendly manner. Perceptions of pressure to confess and interviewer behaviours were measured. Significantly more false confessions were elicited using nonleading questions rather than repetitive questioning. More false confessions were elicited in the friendly interviewer condition than in the stern interviewer condition. Neither interviewer manner nor questioning technique had a significant effect on subjective ratings of pressure to confess. The finding that false confessions may be elicited in the absence of coercive tactics may have implications for informing best practices in investigative interviewing. 
False confessions are one of the most misunderstood causes of error during legal proceedings and contribute to wrongful convictions (Innocence Project, 2017; Leo, 2009). Their elicitation poses a major problem for the Criminal Justice System, the function of which is to deliver justice, punish the guilty, and protect the innocent (Gov.UK, 2017). Although it is acknowledged that police-induced false confessions are the most common type of false confession (Leo, 2009), many legal professionals continue to question the existence of police-induced false confessions, even when DNA evidence confirms a suspect's innocence (Findley \& Scott, 2006; Hirsch, 2005; Kassin \& Gudjonsson, 2004). Therefore, to reduce the risk of false confessions, it is crucial that interviewing officers understand fully the factors contributing to these being elicited.

Kassin and Wrightsman (1985) proposed a theoretical framework that describes three psychologically distinct types of false confession. Coerced-compliant false confessions arise following exposure to coercive or intimidating methods of interrogation. In this case, the suspect makes a public admission of guilt, while maintaining a private belief of innocence, and the short-term benefits of confessing appear to outweigh the long-term costs of confessing. Coerced-internalised false confessions also arise following exposure to extreme interrogation methods. However, unlike coerced-compliant false confessions, this type of false confession involves the suspect internalising a belief of guilt, albeit temporarily. In contrast to coerced-compliant and coerced-internalised false confessions, voluntary false confessions arise from an internal need to confess rather than due to external pres-sure, for example, from the police (Kassin et al., 2010). Reasons for making voluntary false confessions include the protection of the true perpetrator, a desire for notoriety, and a need to be punished (G. H. Gudjonsson \& Pearse, 2011).

In the United States, interrogators are permitted to use confrontational, suggestive, manipulative, and stress-inducing tactics (Bull \& Soukara, 2010; Drizin \& Leo, 2004; Soukara, Bull, Vrij, Turner, \& Cherryman, 2009). Interrogators generally dominate the conversation (Inbau, Reid, Buckley, \& Jayne, 2001) and use various tactics to minimise the perceived negative consequences of confessing and to increase feelings of anxiety associated with denial (Kassin et al., 2010). In contrast to the more accusatorial approach to interviewing often used in the United States (Vallano, Evans, Schreiber Compo, \& Kieckhaefer, 2015), police officers in the United Kingdom commonly use an investigative approach to interviewing (Clarke, Milne, \& Bull, 2011).

However, during the 1980s and early 1990s, police suspects in England and Wales were interrogated rather than interviewed (Williamson, 2006), and the focus on obtaining confessions using unethical methods was a major concern (Shepherd, 1993). The introduction of the PEACE model of interviewing in 1993 resulted in a shift from the interrogative method to the new investigative interviewing approach (Clarke et al., 2011; Griffiths \& Milne, 2006). The PEACE model was designed to replace accusatorial, guilt-presumptive approaches with more ethical, noncoercive, informationgathering approaches, which improve the quality of interviews and information obtained (G. H. Gudjonsson \& Pearse, 2011; Snook, Eastwood, Stinson, Tedeschini, \& House, 2010). Rather than focussing on seeking confessions (Clarke et al., 2011), the PEACE model encourages the use of open questions (Walsh \& Bull, 2012) to encourage suspects to provide accounts of events (Walsh \& Bull, 2010). Techniques such as conversation management are employed to encourage communication between the interviewer and interviewee and to increase the amount of information elicited (Clarke \& Milne, 2001).

During an investigative interview, officers may use techniques and tactics to encourage suspects to provide information and truthful accounts of events (Beune, Giebels, \& Sanders, 2009). However, 
although specific tactics may persuade guilty suspects to tell the truth, proven false confession cases illustrate that exposure to possibly coercive interview tactics can inadvertently also lead to confessions by innocent suspects (Drizin \& Leo, 2004). Therefore, the challenge for investigative interviewers is to obtain true confessions from guilty suspects while minimising the possibility of eliciting false confessions (Horgan, Russano, Meissner, \& Evans, 2012; Meissner, Russano, \& Narchet, 2010). Despite the risks associated with the use of misplaced interview tactics, to date, with a few notable exceptions (Blair, 2007; Klaver, Lee, \& Rose, 2008; Narchet, Meissner, \& Russano, 2011; Russano, Meissner, Narchet, \& Kassin, 2005), not many experimental studies have examined how different interview tactics may contribute to the elicitation of false confessions.

Minimisation is one tactic that can be used to obtain confessions by downplaying the perceived seriousness of an alleged incident and the consequences of confessing (Blair, 2005; Moffa \& Platania, 2009; Russano et al., 2005). When using minimisation, the interviewer expresses sympathy, adopts a friendly demeanour, normalises the crime, and uses "face-saving" strategies that blame the victim and suggest the suspect's behaviour was accidental, provoked, or peer pressured (Horgan et al., 2012; Moffa \& Platania, 2009). These strategies may also imply leniency in sentencing (Kassin, 2015; Kassin \& McNall, 1991; Ofshe \& Leo, 1996, 1997). Minimisation may also elicit false confessions particularly in cases of less serious offences when the interviewer offers a favourable immediate outcome and the suspect feels trapped (Kassin, 2015; Kassin et al., 2010; Kassin \& McNall, 1991). In the United Kingdom, explicit use of minimisation is deemed unacceptable (Kassin et al., 2010; Shawyer, Milne, \& Bull, 2009) and is rarely used (Bull \& Soukara, 2010). However, interviewers may occasionally use more subtle forms of minimisation such as showing concern for the suspect (Soukara et al., 2009), which may contribute to inducing a false sense of security.

Laboratory research documents consistently the coercive nature of minimisation in eliciting confessions. For example, using the computer-crash paradigm (Kassin \& Kiechel, 1996), Klaver et al. (2008) found that minimisation elicited significantly more false confessions in contrast to maximisation. Maximisation is considered a more aggressive form of persuasion used to scare, intimidate, and induce anxiety in suspects (Horgan et al., 2012; Kassin \& McNall, 1991; Narchet et al., 2011). Using a more ecologically valid paradigm, Russano et al. (2005) found that after accusing participants of cheating during a problem-solving task, exposure to minimisation elicited both true and false confessions.

Incorporating the Russano et al. (2005) paradigm, Narchet et al. (2011) found that when trained interrogators believed participants were guilty of cheating, they were more likely to use tactics designed to increase pressure to confess, particularly minimisation and maximisation. In this important body of work documenting the deleterious effects of minimisation, participants were generally presented with preprepared, handwritten false confessions, which they were asked to sign following the false accusation (e.g., Blair, 2007; Klaver et al., 2008; Russano et al., 2005). In a limited number of studies, rather than simply being asked to sign a false confession, participants have been interrogated following a false allegation (e.g., Narchet et al., 2011). Therefore, it would be beneficial to further explore the persuasive nature of minimisation in interviews conducted with mock suspects.

Repetitive questioning is a further tactic, which may induce guilty suspects to confess despite initial denials (Bull \& Soukara, 2010; Penney, 2012). However, this tactic also appears to be associated with the elicitation of false confessions (St-Yves \& Deslauriers-Varin, 2009). Repetitive questioning implies that an initial response is incorrect, or unacceptable, and that a change in response is required (Baxter, Boon, \& Marley, 2006; G. H. Gudjonsson, 2003). Whether used intentionally or unintentionally, repetitive questioning, a form of interrogative pressure, may increase uncertainty, 
heighten the perceived social demands of the situation, and increase susceptibility to interrogative suggestibility (G. H. Gudjonsson \& Clark, 1986; Schaaf, Alexander, \& Goodman, 2008). This tactic, which has been described as aversive, intimidating (Leggett, Goodman, \& Dinani, 2007), and guilt assumptive (Baldwin, 1992), may increase vulnerability during an investigative interview.

Repetitive questioning is not recommended by the PEACE model of interviewing (Walsh \& Bull, 2012). However, an examination of police interview practices in England and Wales reported the frequent use of repetitive questioning when attempting to obtain information from suspects (Soukara et al., 2009). Although the negative effects associated with repetitive questioning are acknowledged (St-Yves \& Deslauriers-Varin, 2009), to date, there has been no empirical examination of the extent to which repetitive questioning may be associated with suspects making false confessions.

Leading questions, another form of interrogative pressure (Baxter et al., 2006), which prompt an interviewee to respond in a certain way (G. H. Gudjonsson, 2003; G. H. Gudjonsson \& Clark, 1986; Soukara et al., 2009), have also been associated with known false confession cases (Garrett, 2010). Asking leading questions, which may contain plausible but misleading information, may result in memory for an event being supplemented, distorted, and reconstructed (Busey \& Loftus, 2007; Loftus, 1975, 1979, 2002). The use of leading questions can also introduce erroneous information, impair accurate recall, induce uncertainty, and make it difficult to differentiate sources of information (G. H. Gudjonsson \& Clark, 1986; Loftus, 1975, 2002, 2005).

Leading questions, which the PEACE model discourages (Walsh \& Bull, 2015) in the United Kingdom, are also a possible breach of Sections 76 and 78 of the Police and Criminal Evidence Act 1984 (Clarke \& Milne, 2001). Leading questions are generally observed infrequently in interviews conducted by officers in the United Kingdom (Clarke et al., 2011; Read, Powell, Kebbell, Milne, \& Steinberg, 2014). However, Soukara et al. (2009) reported the use of leading questions, which did not contain misleading information, in 30 of the 31 confession interviews with suspects conducted in an English police force. Due to the dangers associ-ated with leading questions, it would be prudent to examine whether this practice could potentially elicit false confessions.

The dangers associated with coercive interview tactics may be particularly salient during interviews with vulnerable individuals. There is no universal definition of what constitutes a vulnerable witness (Bull, 2010). However, those who might be considered vulnerable include child witnesses (Bull, 2010), individuals with mental illnesses and personality disorders (O'Mahony, Milne, \& Grant, 2012), and individuals with intellectual disabilities (G. Gudjonsson \& Joyce, 2011). For example, individuals with an intellectual disability may be more susceptible to leading questions (Bowles \& Sharman, 2014) and misleading questions (Henry \& Gudjonsson, 2007). However, research indicates that when individuals with learning disabilities are questioned in an appropriate manner using questions that are nonleading, simple, and free from abstract words or ideas (Jacobson, 2008), they can be capable of providing accurate statements (Milne \& Bull, 2001).

In addition to the use of coercive tactics, interviewer attitudes and demeanours may also contribute to determining the outcome of an interview (e.g., Bain \& Baxter, 2000; Baxter, Jackson, \& Bain, 2003) and influence the decision to make a true or a false confession (Holmberg \& Christianson, 2002; Leo, 2009; Walsh \& Bull, 2012). Ethical interviewing, exemplified by the PEACE approach (Heydon, 2012), involves using a fair approach that increases the likelihood of eliciting a truthful account of events while reducing a suspect's stress and uncer-tainty (Milne \& Bull, 1999). However, in certain situations, an interviewer's behaviour may be perceived as neg-ative, thereby increasing a suspect's resistance to cooperate (Holmberg \& Christianson, 2002). This may occur, for example, 
when officers are under pressure to elicit information within time restraints, or if a suspect does not respond to questions.

If an aggressive interviewer manner is adopted, even unintentionally, inappropriate pressure may be applied (Baldwin, 1992; Baxter, 2004). An abrupt and/or aggressive interviewer manner may induce anxiety and feelings of powerlessness in a suspect, thereby creating psychological distance between the interviewee and interviewer and increasing susceptibility to suggestibility (Bain \& Baxter, 2000). It has been hypothesised that under these circumstances, vulnerability to falsely confessing may increase (Baxter \& Boon, 2000; G. H. Gudjonsson \& Lister, 1984). An accusatorial style of interviewing that reduces self-confidence and does not enable a suspect to state her or his innocence may also result in a false confession (Leo, 2009). Therefore, there is a need to examine empirically whether interviewer manner may elicit false confessions.

To summarise, specific questioning techniques and interviewer manners may adversely affect a suspect and contribute to false confessions. Previous research examining interview tactics as predictors of false confessions has tended to focus on minimisation and maximisation tactics, which are more commonly used by interrogators in the United States (e.g., Blair, 2007; Klaver et al., 2008; Narchet et al., 2011; Russano et al., 2005). To date, there has been no empirical examination of repetitive questioning and leading questions as predictors of labora-tory-induced false confessions. Additionally, although it has been documented that an abrupt and aggressive interviewer manner may increase vulnerability during a police interview (Bain \& Baxter, 2000; Baxter \& Boon, 2000; Blandon-Gitlin, Sperry, \& Leo, 2011), interviewer manner as a predictor of laboratory-induced false confes-sions has not been examined.

The present study adopted a novel approach in which the combined effects of questioning technique and inter-viewer manner on false confessions and perceptions of pressure to confess were examined. In an attempt to improve realism, the study incorporated a new paradigm in which participants were interviewed following a false accusation of theft. The false allegation was serious in nature, personally meaningful to those involved and free from ambiguity. Based on previous formative work (e.g., Baxter et al., 2003; Bull \& Soukara, 2010; Klaver et al., 2008; Narchet et al., 2011; Russano et al., 2005), it was predicted that coercive questioning techniques and a stern interviewer manner would elicit more false confessions and higher ratings of perceived pressure to confess in contrast to noncoercive questioning techniques and a friendly interviewer manner.

\section{2 | METHOD}

\section{1 | Participants and design}

A total of 120 members of the public and students were recruited. Fifty-three males and 67 females aged 16 to 62 years $(M=28.21, S D=10.36)$ participated. Participants were randomly assigned to one of eight experimental conditions in a 2 demeanour (friendly vs. stern) $\times 4$ questioning technique (minimisation, repetitive questioning, leading questions, and nonleading questions) betweenparticipants design (see Section 3.3 for further details).

\subsection{Confederates}

Four male undergraduate students responded to an advert in which confederates for a research project were required. The principal investigator trained the confederates to interview participants in each of the eight experimental conditions following a false allegation of theft. The confederates were trained to use the interviewer demeanours outlined by Bain and Baxter (2000), and they conducted the interviews using preprepared scripts (as outlined within Section 3.3). 
2173.1 Interviewer behaviour rating scale (Bain \& Baxter, 2000)

218 A5-point Likert scale was used to assess the extent to which the confederate interviewers displayed 21918 interviewer behaviours ( 1 = not at all and 5 = very). The behaviours were as follows: nervous, severe, friendly, understanding, assertive, confident, professional, firm, respectful, positive, formal, warm, stern, organised, effective, authoritative, competent, and negative. This tool has been used in studies examining the effect of interviewer behaviour on interrogative suggestibility (e.g., Bain \& Baxter, 2000; Baxter et al., 2003) and is considered a reliable method of measuring differences in perceptions of interviewer behaviour.

\subsection{Perceived pressure to confess scale}

Incorporating a method used by Russano et al. (2005), we used an 11-point Likert scale to rate the extent to which participants experienced pressure to confess $(0=$ no pressure and $10=$ extreme pressure).

\subsection{Procedure}

A pilot study was conducted to confirm that interviewer behaviour differentiated the stern and friendly interviewer conditions. The four confederates were filmed conducting interviews in a stern and friendly manner. University students $(n=104)$ rated the interviewers' behaviour using the 18item rating scale described above.

In the main study, participants were invited to participate in a study examining the relationship between personality traits and task performance. Participants were tested individually and learnt that on successful comple-tion of two personality questionnaires, they might be entitled to receive a $£ 10$ gift voucher. The vouchers were placed on the table at which the participant was seated. While the participant completed the first questionnaire, the researcher left the room for two minutes on the pretext of speaking to another participant. On return, and after the participant had completed the questionnaire, the researcher counted the vouchers, announced that one voucher was missing, and falsely accused the participant of theft. In reality, there was no missing voucher, and none of the participants questioned the fact that they did not know how many vouchers were initially placed on the table. The researcher excused herself or himself again, and two minutes later, one of the four confederates entered the room.

The confederate introduced himself as part of the research team and advised the participant that it was nec-essary to ask a few questions about the missing voucher. Incorporating Bain and Baxter's (2000) interviewer man-ner technique, the confederate adopted either a friendly or stern manner. In the friendly condition, in order to build rapport and appear warm and friendly, the confederate introduced himself using his first name, maintained eye contact with the participant, smiled, and adopted a relaxed posture. In the stern condition, in order to appear formal and abrupt, the confederate introduced himself using his full name, did not smile, and adopted an assertive and authoritative stance. The confederate then asked the participant to recall the event in her or his own words and said he would make notes while listening to the participant's account of the event. Following this free recall stage, and adhering to the relevant script, the confederate asked a number of predetermined questions about the alleged incident and again noted the participant's responses.

In the minimisation condition, the confederate showed concern towards the participant and offered face-saving strategies, for example, by stating, "Don't worry" and "I'm sure you didn't realise that this was a big deal." In the repetitive questioning condition, participants were asked six times "Did 
you take the missing voucher?" In the leading question condition, participants were asked questions that prompted a desired response, for example, "The vouchers were clearly visible on the table, so it would have been easy to take one wouldn't it?" and "So you were alone in the room for a few minutes, weren't you?" Last, in the nonleading question condition, which adopted the noncoercive, information-gathering approach advocated by PEACE, confederates asked questions such as "Who was in the room at the start of the experiment?" "Did anyone else come into the room?" and "Were you alone in the room at any point?"

At the end of the questioning stage, the confederate summarised the information provided and asked the participant if she or he had anything else to add. Participants received their "statement," which included their responses and the declaration "I accept responsibility for the missing voucher," which constituted a false confession. The confederate asked the participant to sign the statement, and participants who refused to sign after the first request were prompted up to two more times. The confederate left the room, and the researcher reentered and advised the participant that the study was examining false confessions. The researcher reestablished consent and asked the participant to complete the two rating scales. Last, participants were debriefed fully.

\section{ETHICAL CONSIDERATIONS}

Ethical approval was granted by the university's research ethics committee. Participants could not be exposed to accusations of a very serious nature or subjected to highly stressful, prolonged interviews. Therefore, short interviews in which participants were accused of stealing a $£ 10$ gift voucher were conducted. Due to the nature of the subject being investigated, the use of deception was necessary. If a participant appeared upset or annoyed following the false accusation and/or during the interview, the session terminated immediately. One participant appeared to be upset after the researcher delivered the false accusation. A second participant withdrew from the study after the confederate entered the room and before the interview commenced. In both cases, the researcher debriefed the participant immediately and destroyed the participant's data. If, fol-lowing the false accusation, a participant attempted to prove that she or he did not have the voucher, for example, by asking the researcher or confederate to search a bag or pockets, the participant would have been told it was not possible to conduct such a search. In accordance with the British Psychological Society (2014) Code of Human Research Ethics, participants were debriefed fully at the end of the study and reminded that they could withdraw their data.

\section{RESULTS}

\subsection{Pilot study}

One-way multivariate analysis of variance was conducted, which found significant differences in ratings between the stern and friendly interviewer conditions for 11 of the 18 interviewer behaviours noted above (see Table 1). Interviewers in the stern condition were rated significantly more severe: $F(1,102)=148.32, p<0.001$, partial $\eta 2=0.60$; assertive: $F(1,102)=16.33, p<0.001$, partial $\eta 2=0.14$; firm: $F(1,102)=41.73, p<0.001$, partial $\eta 2=0.29$; stern: $F(1,102)=79.37, p<$ 0.001 , partial $\eta 2=0.44$; authoritative: $F(1,102)=51.53, p<0.001$, partial $\eta 2=0.34$; and negative: $F$ $(1,102)=57.91, p<0.001$, partial $\eta 2=0.36$. Interviewers in the friendly condition were rated significantly more friendly: $F(1,102)=110.70, p<0.001$, partial $\eta 2=0.52$; understanding: $F(1,102)$ $=26.08, p<0.001$, partial $\eta 2=0.20$; respectful: $F(1,102)=29.71, p<0.001$, partial $\eta 2=0.23$; positive: $F(1,102)=34.38, p<0.001$, partial $\eta 2=0.25$; and warm: $F(1,102)=55.50, p<0.001$, partial $\eta 2=0.35$. 
5.2 Main study: Manipulation check to examine the effect of interviewer manner on interviewer behaviour ratings

One-way multivariate analysis of variance was conducted, which found significant differences in ratings between the stern and friendly interviewer conditions for four of the 18 interviewer behaviours (see Table 2). Interviewers in the stern condition were rated significantly more severe: $\mathrm{F}$ $(1,118)=10.30, p=0.002$, partial $\eta 2=0.08$; and stern: $F(1,118)=11.45, p=0.001$, partial $\eta 2=$ 0.10 . Interviewers in the friendly condition were rated significantly more friendly: $F(1,118)=28.19$, $p<0.001$, partial $\eta 2=0.20$; and understanding: $F(1,118)=13.39, p<0.001$, partial $\eta 2=0.11$.

\subsection{Effect of interviewer manner and questioning technique on false confessions}

The number of false confessions obtained per experimental condition is shown in Table 3.

None of the participants falsely confessed during the questioning stage of the interview. Each false confession was obtained when the confederate asked the participant to sign the statement.

Logistic regression was performed to examine the effects of a stern interviewer manner and coercive questioning techniques on the likelihood of participants making a false confession. As the variable "questioning technique" contained more than two levels, the nonleading question condition was selected as a baseline group against which the other groups were compared. The model containing the predictors was statistically significant, $\chi 2(4, N=120)=10.47, p=0.033$, indicating that it differentiated participants who signed the false confession from nonconfessors. The model accounted for between $8.4 \%$ and $11.8 \%$ of the variance in behaviour when asked to sign a false confession and correctly classified $71.7 \%$ of cases. One predictor (repetitive questioning) made a statistically significant contribution to the model (see Table 4). Each unit increase in repetitive questioning was associated with a decrease in the odds of making a false confession by a factor of $0.171(95 \% \mathrm{Cl}[0.05,-0.62])$.

\subsection{Effect of interviewer manner and questioning technique on perceived pressure to confess}

To examine whether interviewer manner and questioning technique influenced perceptions of pressure to confess, a 2 (stern vs. friendly) $\times 4$ (minimisation vs. repetitive questioning vs. leading questions vs. nonleading questions) between-groups analysis of variance was conducted. Neither interviewer manner nor questioning technique influenced the ratings of pressure to confess: $F(1$, $112)=1.18, p=0.279$; and $F(3,112)=0.57, p=0.634$, respec-tively. The interaction between interviewer manner and questioning technique was not significant: $F(3,112)=1.01, p=0.391$. Mean ratings for perceived pressure to confess per experimental condition are shown in Table 5. Further analysis using an independent samples $t$ test revealed that false confessors rated perceived pressure to confess significantly higher than did nonconfessors: $\mathrm{t}(118)=2.64, \mathrm{p}=0.009, \mathrm{\eta} 2=0.06$.

\subsection{False confessions obtained per interviewer}

Table 6 shows the number of false confessions obtained per interviewer. Due to the low number of false confessions elicited by Interviewer 2, statistical analysis was not possible.

\section{DISCUSSION}

The present study represents a first attempt to examine the combined effects of questioning techniques and inter-viewer manner on false confessions. Almost a third of the participants signed a false confession, and the majority of those confessed immediately when presented with their statement. In the current study, participants appeared to confess despite a lack of incriminating evidence, in the absence of extreme pressure, and despite being unaware of any consequences of 
confessing. It was hypothesised that coercive questioning and a stern interviewer manner would elicit more false confessions and higher ratings of perceived pressure to confess than would noncoercive questioning and a friendly interviewer manner. However, contrary to predictions, in the current study, the nonleading question condition appeared to elicit the greatest number of false confessions.

The nonleading question condition was characterised by a lack of coercive tactics and included the use of open-ended questions designed to discover "the truth." Nevertheless, noncoercive questioning techniques can be psycho-logically manipulative. Indeed, if participants in this questioning condition felt at ease, this may have heightened a perception of trust between interviewee and interviewer, thereby possibly increasing vulnerability to complying with the request to sign the false confession. Whereas coercive tactics including minimisation may encourage innocent suspects to confess (e.g., Blair, 2005; Klaver et al., 2008; Russano et al., 2005), the present results therefore suggest that, under certain conditions, false confessions may occur in the absence of intimidating and coercive tactics. Fur-ther research is therefore advised to examine systematically the extent to which, and in which contexts, noncoercive questioning techniques may result in the elicitation of false confessions.

Results indicate further that repetitive questioning elicited significantly fewer false confessions in comparison with nonleading questions. The inference of guilt conveyed by repeatedly asking participants if they had taken a voucher may have provoked defiance, thereby encouraging continued denial of theft. Alternatively, if participants felt aggrieved rather than intimidated by the frequent challenging of their responses, an adversarial interaction may have unwittingly occurred (Russano, Narchet, \& Kleinman, 2014), thereby possibly reducing the likelihood of responses being altered and false confessions being obtained.

Despite the coercive nature of repetitive questioning (e.g., Alison, Kebbell, \& Leung, 2008), which is attrib-uted to verified false confession cases (St-Yves \& Deslauriers-Varin, 2009), the current findings suggest that repetitive questioning may have an antagonistic effect. From this perspective, it appears that repetitive questioning may increase resistance to altering responses, thereby reducing the risk of false confessions. The current finding was unexpected, and further research examining repetitive questioning as a predictor of false confessions appears warranted.

Minimisation was not a significant predictor of false confessions in the present study. However, providing sup-port to previous findings (e.g., Klaver et al., 2008; Narchet et al., 2011; Russano et al., 2005), the use of minimisation appeared to elicit false confessions. Participants in this condition, who were most likely unaware of this subtle form of persuasion, may have believed that the interviewer had their best interests at heart when making comments such as "Don't worry." This proposition is supported by the finding that mean ratings of pressure to confess were lower in the minimisation condition than in the repetitive questioning and leading question conditions, which suggests that participants were unaware of the use of coercion.

Although leading questions were not a significant predictor of false confessions, the use of this tactic accounted for almost a quarter of the total false confessions obtained. Due to the brief time lapse between the false accusation and the interview, memory for the event should have been relatively accurate and therefore should have helped guard against the risk of yielding to leading questions (cf. Loftus, 2005). However, the coercive nature of leading questions may have created uncertainty about the situation (G. H. Gudjonsson \& Clark, 1986), resulting in participants appearing to accept the suggestion that they were responsible for the missing voucher. The present findings suggest that even if questioning occurs almost immediately after an alleged incident, leading questions may 
create doubt about an event, increase susceptibility to accepting suggestions, and contribute to false confessions being made.

The finding that there was no significant main effect of interviewer manner on false confessions may have been due to the experimental manipulations. In contrast to the findings of the pilot study, in the main study, significant differences in interviewer behaviour ratings between the stern and friendly conditions were obtained for four behaviours only. In the pilot study, participants rated the interviewers' behaviour after watching video recordings of a simulated interview. In comparison, in the main study, participants completed the behaviour rating scale after the confederate interviewed them about an alleged theft. In the main study, the potentially stressful nature of the situation may therefore have contributed, for example, to the more negative perceptions of the friendly interviewer when rating behaviours such as "firm," "warm," and "authoritative," thereby explaining the lack of effect of interviewer manner on false confessions. Additionally, several of the behaviours listed in the behaviour rating form describe similar demeanours (e.g., assertive, confident, and authoritative). Reducing the number of behaviours being measured in future studies may consequently facilitate the interpretation of findings.

Nevertheless, it is noteworthy that in the current study a stern interviewer manner elicited fewer false confessions than did a friendly interviewer manner. It has been proposed that exposure to a stern interviewer manner may result in the application of inappropriate pressure (e.g., Baxter, 2004) and increase the psychological distance between an interviewee and interviewer (e.g., Bain \& Baxter, 2000), thereby heightening the risk of obtaining a false confession (e.g., Baxter \& Boon, 2000). However, the present findings suggest that exposure to an interviewer perceived as hostile and rude may increase resistance to making a false confession. Thus, in the present study, the stern manner, which appears to have elicited feelings of annoyance and disrespect, appears to have reduced the likelihood of cooperation when asked to sign a false confession (cf. Holmberg \& Christianson, 2002).

Data analysis found no significant effect of interviewer manner and questioning technique on pressure to con-fess. Although this finding was unexpected, it is noteworthy that mean ratings for pressure to confess were higher in the stern, coercive questioning conditions in contrast to the friendly coercive questioning conditions. Also, of note is the finding that participants in the friendly nonleading question condition rated pressure to confess higher than did participants in most of the other questioning conditions (see Table 5). It is possible that, in the friendly nonleading question condition, an informal and understanding interviewer manner combined with a lack of coercive questioning created a more subtle, or covert, form of psychological manipulation resulting in participants experiencing pressure to cooperate with the request to sign the false confession. Meriting further investigation, this finding suggests that interactions between interviewer manner and questioning technique should not be discounted when considering perception of pressure to confess.

When interpreting the present results, several factors should be borne in mind, which may limit the extent to which the findings generalise to other contexts and populations. First, in comparison with police suspects, participants could terminate the interview at any point, and they did not run the risk of encountering any longer term negative consequences due to falsely confessing. Second, the confederates were aware of the aims of the research, which may have influenced their behaviour in ways other than intended. Third, although each confederate received the same training and adopted a uniform approach to interviewing, the percentage of false confessions obtained per interviewer (relative to the number of interviews conducted) varied considerably. The influence of interpersonal dynamics, which were not controlled for, might therefore explain the variation in the number of 
false confessions obtained to a degree. Factors such as the relationship between the interviewer and interviewees' age and gender may have mediated the interpersonal relationship and influenced the outcome of the interview. For example, although the participants' experience was subjective, a 19year-old female false confessor said she felt intimidated being interviewed by an older man. In contrast, a 40-year-old male nonconfessor said he was "Not at all concerned or intimidated" while being interviewed by a much younger man. Last, as the sample size was small and would have limited the statistical power, future research using a larger sample is required.

In conclusion, the present findings suggest that false confessions may arise following exposure to both noncoercive psychologically manipulative techniques and coercive interview techniques. The use of friendly interviewer manners during the interrogation of suspects, found to be associated with the elicitation of false confessions in the current study, may have implications for the design of investigative interviews. With this in mind, the present findings may be particularly relevant in the United Kingdom where the PEACE model of interviewing recommends the use of nonleading, openended questions (Soukara et al., 2009; Walsh \& Bull, 2012) and rapport building (Meissner et al., 2014) to facilitate the information-gathering approach.

Furthermore, in addition to considering the role of questioning techniques and interviewer manners in eliciting false confessions, possible interactions between different interview techniques as well as the age and gender of interviewers and interviewees may contribute to outcomes and warrants further examination. Overall, it is important that findings of current and previous research are reflected in training procedures, and that research efforts are continued to identify risk factors for false confessions. Implementing procedures, which help reduce the likelihood of suspects' statements subsequently being found to be erroneous, not only will offer protection for suspects and interviewing officers but will also help target police resources appropriately.

\section{REFERENCES}

Alison, L., Kebbell, M., \& Leung, J. (2008). A facet analysis of police officers' self-reported use of suspect-interviewing strategies and their discomfort with ambiguity. Applied Cognitive Psychology, 22, 1072-1087. https://doi.org/10.1002/acp.1408

Bain, S. A., \& Baxter, J. S. (2000). Interrogative suggestibility: The role of interviewer behaviour. Legal and Criminological Psychology, 5, 123-133. https://doi.org/10.1348/135532500168029

Baldwin, J. (1992). Videotaping police interviews with suspects- An evaluation. Police Research Series: Paper No. 1. London: Home Office.

Baxter, J. S. (2004). Managing interrogative pressure in police interviews. The Police Journal, 77, 303-308. https://doi.org/ 10.1350/pojo.77.4.303.58967

Baxter, J. S., \& Boon, J. C. W. (2000). Interrogative suggestibility: The importance of being earnest. Personality and Individual Differences, 28, 753-762. https://doi.org/10.1016/S0191-8869(99)001361

Baxter, J. S., Boon, J. C. W., \& Marley, C. (2006). Interrogative pressure and responses to minimally leading questions. Personality and Individual Differences, 40, 87-98. https://doi.org/10.1016/j.paid.2005.06.017

Baxter, J. S., Jackson, M., \& Bain, S. A. (2003). Interrogative suggestibility: Interactions between interviewees' self-esteem and interviewer style. Personality and Individual Differences, 35, 12851292. https://doi.org/10.1016/S0191-8869(02)00349-5 
Beune, K., Giebels, E., \& Sanders, K. (2009). Are you talking to me? Influencing behaviour and culture in police interviews. Psychology, Crime and Law, 15, 597-617. https://doi.org/10.1080/10683160802442835

Blair, J. P. (2005). A test of the unusual false confession perspective using cases of proven false confessions. Criminal Law Bulletin, 41, 127-144.

Blair, J. P. (2007). The roles of interrogation, perception and individual differences in producing compliant false confessions. Psychology, Crime and Law, 13, 173-186. https://doi.org/10.1080/10683160600632801

Blandon-Gitlin, I., Sperry, K., \& Leo, R. (2011). Jurors believe interrogation tactics are not likely to elicit false confessions: Will expert witness testimony inform them otherwise? Psychology, Crime and Law, 17, 239-260. https://doi.org/10.1080/ 10683160903113699

Bowles, P. V., \& Sharman, S. J. (2014). A review of the impact of different types of leading interview questions on child and adult witnesses with intellectual disabilities. Psychiatry, Psychology and Law, 21(2), 205-217. https://doi.org/10.1080/ 13218719.2013.803276

British Psychological Society (2014). Code of human research ethics. Leicester: British Psychological Society.

Bull, R. (2010). The investigative interviewing of children and other vulnerable witnesses:

Psychological research and work-ing/professional practice. Legal and Criminological Psychology, 15,5-23. https://doi.org/10.1348/014466509X440160

Bull, R., \& Soukara, S. (2010). Four studies of what really happens in police interviews. In G. D. Lassiter, \& C. A. Meissner (Eds.), Police interrogation and false confessions: Current research, practice, and policy recommendations (pp. 81-95). Wash-ington, DC: APA.

Busey, T. A., \& Loftus, G. R. (2007). Cognitive science and the law. Trends in Cognitive Sciences, 11, 111-117. https://doi.org/10.1016/j.tics.2006.12.004

Clarke, C., \& Milne, R. (2001). A national evaluation of the PEACE investigative interviewing course. London: Home Office. Clarke, C., Milne, R., \& Bull, R. (2011). Interviewing suspects of crime: The impact of PEACE training, supervision and the presence of a legal advisor. Journal of Investigative Psychology and Offender Profiling, 8(2), 149-162. https://doi.org/ 10.1002/jip.144

Drizin, S. A., \& Leo, R. A. (2004). The problem of false confessions in the post-DNA world. North Carolina Law Review, 82, 891-1008.

Findley, K. A., \& Scott, M. S. (2006). Multiple dimensions of tunnel vision in criminal cases. The Wisconsin Law Review, 2, 291-397.

Garrett, B. L. (2010). The substance of false confessions. Stanford Law Review, 62, 1051-1119.

Gov.UK. (2017). [online]. Law and the justice system. Available from:

https://www.gov.uk/government/topics/law-and-the-justice-system [Accessed 7th May 2017].

Griffiths, A., \& Milne, R. (2006). Will it all end in tiers? Police interviews with suspects in Britain. In T. Williamson (Ed.), Investigative interviewing. Rights, research, regulation (pp. 167-189). Willan: Devon. 
Gudjonsson, G., \& Joyce, T. (2011). Interviewing adults with intellectual disabilities. Advances in Mental Health and Intellectual Disabilities, 5(2), 16-21. https://doi.org/10.5042/amhid.2011.0108.

Gudjonsson, G. H. (2003). The psychology of interrogations and confessions: A handbook. Chichester: Wiley.

Gudjonsson, G. H., \& Clark, N. K. (1986). Suggestibility in police interrogation: A social psychological model. Social Behaviour, 1,83-104.

Gudjonsson, G. H., \& Lister, S. (1984). Interrogative suggestibility and its relationship with perceptions of self-concept and control. Journal of the Forensic Science Society, 29, 261-269. https://doi.org/10.1016/S0015-7368(84)72302-4

Gudjonsson, G. H., \& Pearse, J. (2011). Suspect interviews and false confessions. Current Directions in Psychological Science, 20,33-37. https://doi.org/10.1177/0963721410396824

Henry, L., \& Gudjonsson, G. (2007). Individual and developmental differences in eyewitness recall and suggestibility in children with intellectual disabilities. Applied Cognitive Psychology, 21, 361-381. https://doi.org/10.1002/acp.1280

Heydon, G. (2012). Helping the police with their enquiries: Enhancing the investigative interview with linguistic research. The Police Journal, 85, 101-122.

https://doi.org/10.1350/pojo.2012.85.2.581

Hirsch, A. (2005). Threats, promises, and false confessions: Lessons of slavery. Howard Law Journal, 49,31-61.

Holmberg, U., \& Christianson, S. (2002). Murderers' and sexual offenders' experiences of police interviews and their inclination to admit or deny crimes. Behavioral Sciences and the Law, 20,31-45. https://doi.org/10.1002/bsl.470

Horgan, A. J., Russano, M. B., Meissner, C. A., \& Evans, J. R. (2012). Minimization and maximization techniques: Assessing the perceived consequences of confessing and confession diagnosticity. Psychology, Crime and Law, 18,65-78. https://doi. org/10.1080/1068316X.2011.561801.

Inbau, F. E., Reid, J. E., Buckley, J. P., \& Jayne, B. C. (2001). Criminal interrogation and confessions (4th ed.). Gaithersburg, MD: Aspen.

Innocence Project. (2017). [online]. False confessions or admissions. Available from:https://www.innocenceproject.org/causes/false-confessions-admissions/ [Accessed 31st Jan 2017].

Jacobson, J. (2008). [online]). No one knows: Police responses to suspects with learning disabilities and learning difficulties: A review of policy and practice. London: Prison Reform Trust.

Kassin, S. M. (2015). The social psychology of false confessions. Social Issues and Policy Review, 9,25-51. https://doi.org/10.1111/sipr.12009

Kassin, S. M., Drizin, S. A., Grisso, T., Gudjonsson, G. H., Leo, R. A., \& Redlich, A. D. (2010). Policeinduced confessions: Risk factors and recommendations. Law and Human Behavior, 34,3-38. https://doi.org/10.1007/s10979-009-9188-6 
Kassin, S. M., \& Gudjonsson, G. H. (2004). The psychology of confessions: A review of the literature and issues. Psychological Science in the Public Interest, 5,33-67. https://doi.org/10.1111/j.15291006.2004.00016.x

Kassin, S. M., \& Kiechel, K. L. (1996). The social psychology of false confessions: Compliance, internalization and confabulation. Psychological Science, 7, 125-128. https://doi.org/10.1111/j.1467-9280.1996.tb00344.x

Kassin, S. M., \& McNall, K. (1991). Police interrogations and confessions. Law and Human Behavior, 15, 233-251. doi: 0147-7307/91/0600-0233506.50/0

Kassin, S. M., \& Wrightsman, L. S. (1985). Confession evidence. In S. Kassin, \& L. Wrightsman (Eds.), The psychology of evidence and trial procedure (pp. 67-94). Beverly Hills, CA: Sage.

Klaver, J. R., Lee, Z., \& Rose, V. G. (2008). Effects of personality, interrogation techniques and plausibility in an experimental false confession paradigm. Legal and Criminological Psychology, 13,71-88. https://doi.org/10.1348/135532507X193051

Leggett, J., Goodman, W., \& Dinani, S. (2007). People with learning disabilities' experiences of being interviewed by the police. British Journal of Learning Disabilities, 35, 168-173. https://doi.org/10.1111/j.1468-3156.2007.00458.x

Leo, R. A. (2009). False confessions: Causes, consequences and implications. The Journal of the American Academy of Psychiatry and the Law, 37, 332-343.

Loftus, E. F. (1975). Leading questions and the eyewitness report. Cognitive Psychology, 7, 560-572. https://doi.org/10.1016/0010-0285(75)90023-7

Loftus, E. F. (1979). Reactions to blatantly contradictory information. Memory and Cognition, 7, 368374. https://doi.org/10.3758/BF03196941

Loftus, E. F. (2002). Memory faults and fixes. Issues in Science and Technology, 18,41-50.

Loftus, E. F. (2005). Planting misinformation in the human mind: A 30-year investigation of the malleability of memory. Learning and Memory, 12, 361-366. https://doi.org/10.1101/Im.94705.

Meissner, C. A., Redlich, A. D., Michael, S. W., Evans, J. R., Camilletti, C. R., Bhatt, S., \& Brandon, S. (2014). Accusatorial and information-gathering interrogation methods and their effects on true and false confessions: A meta-analytic review. Journal of Experimental Criminology, 10, 459-486. https://doi.org/10.1007/s11292-014-9207-6

Meissner, C. A., Russano, M. B., \& Narchet, F. M. (2010). The importance of a laboratory science for improving the diagnostic value of confession evidence. In G. D. Lassiter, \& C. Meissner (Eds.), Interrogations and confessions: Current research, practice, and policy (pp. 111-126). Washington, DC: APA.

Milne, R., \& Bull, R. (1999). Investigative interviewing: Psychology and practice. Chichester: Wiley.

Milne, R., \& Bull, R. (2001). Interviewing witnesses with learning disabilities for legal purposes. British Journal of Learning Disabilities, 29,93-97. https://doi.org/10.1046/j.1468-3156.2001.00139.x

Moffa, M., \& Platania, J. (2009). The differential importance of the evidence and the expert on perceptions of confessions. Journal of Forensic Psychology Practice, 9, 280-298. https://doi.org/10.1080/15228930902935719 
Narchet, F. M., Meissner, C. A., \& Russano, M. B. (2011). Modelling the influence of investigator bias on the elicitation of true and false confessions. Law and Human Behavior, 35, 452-465. https://doi.org/10.1007/s10979-010-9257-x

Ofshe, R. J., \& Leo, R. A. (1996). The decision to confess falsely: Rational choice and irrational action. Denver University Law Review, 74, 979-1122.

Ofshe, R. J., \& Leo, R. A. (1997). The social psychology of police interrogation. The theory and classification of true and false confessions. Studies in Law, Politics and Society, 16, 189-251.

O'Mahony, B. M., Milne, B., \& Grant, T. (2012). To challenge, or not to challenge? Best practice when interviewing vulnerable suspects. Policing, 6, 301-313. https://doi.org/10.1093/police/pas.

Penney, S. (2012). Police questioning in the charter era: Adjudicative versus regulatory rule making and the problem of false confessions. Supreme Court Law Review, 57, 263-292.

Read, J., Powell, M., Kebbell, M., Milne, B., \& Steinberg, R. (2014). Evaluating police interviewing practices with suspects in child-sexual abuse cases. Policing and Society, 24, 523. https://doi.org/10.1080/10439463.2013.784297

Russano, M. B., Meissner, C. A., Narchet, F. M., \& Kassin, S. M. (2005). Investigating true and false confessions within a novel experimental paradigm. Psychological Science, 16, 481-486. https://doi.org/10.1111/j.0956-7976.2005.01560.x

Russano, M. B., Narchet, F. M., \& Kleinman, S. M. (2014). Analysts, interpreters, and intelligence interrogations: Perceptions and insights. Applied Cognitive Psychology, 28, 829-846. https://doi.org/10.1002/acp.3070

Schaaf, J. M., Alexander, K. W., \& Goodman, G. S. (2008). Children's false memory and true disclosure in the face of repeated questions. Journal of Experimental Child Psychology, 100, 157185. https://doi.org/10.1016/j.jecp.2007.09.002

Shawyer, A., Milne, B., \& Bull, R. (2009). Investigative interviewing in the UK. In T. Williamson, B. Milne, \& R. Bull (Eds.), International developments in investigative interviewing (pp. 24-38). Devon: Willan.

Shepherd, E. (1993). Ethical interviewing. In E. Shepherd (Ed.), Aspects of police interviewing. Issues in criminological and legal psychology, No 18. Leicester, UK: British Psychological Society.

Snook, B., Eastwood, J., Stinson, M., Tedeschini, J., \& House, J. C. (2010). Reforming investigative interviewing in Canada. Canadian Journal of Criminology and Criminal Justice, 52, 215-229. https://doi.org/10.3138/cjccj.52.2.215

Soukara, S., Bull, R., Vrij, A., Turner, M., \& Cherryman, J. (2009). What really happens in police interviews of suspects? Tactics and confessions. Psychology, Crime and Law, 15, 493-506. https://doi.org/10.1080/10683160802201827

St-Yves, M., \& Deslauriers-Varin, N. (2009). The psychology of suspects' decision-making during interrogation. In R. Bull, T. Valentine, \& T. Williamson (Eds.), Handbook of psychology of investigative interviewing: Current developments and future directions (pp. 1-16). Chichester: Wiley.

Vallano, J. P., Evans, J. R., Schreiber Compo, N., \& Kieckhaefer, J. M. (2015). Rapport-building during witness and suspect interviews: A survey of law enforcement. Applied Cognitive Psychology, 29, 369-380. https://doi.org/10.1002/acp.3115 
631 Walsh, D., \& Bull, R. (2010). What really is effective in interviews with suspects? A study comparing

632 interviewing skills against interviewing outcomes. Legal and Criminological Psychology, 15, 305-321.

633 https://doi.org/10.1348/135532509X463356

634 Walsh, D., \& Bull, R. (2012). How do interviewers attempt to overcome suspects' denials? Psychiatry, 635 Psychology and Law, 19, 151-168. https://doi.org/10.1080/13218719.2010.543756

636 Walsh, D., \& Bull, R. (2015). Interviewing suspects: Examining the association between skills,

637 questioning, evidence disclosure, and interview outcomes. Psychology, Crime and Law, 21, 661-680.

638 https://doi.org/10.1080/1068316X.2015.1028544

639 Williamson, T. (Ed.) (2006). Investigative interviewing: Rights, research, regulation. Devon: Willan. 